Vol. 1, No. 2, Desember 2020

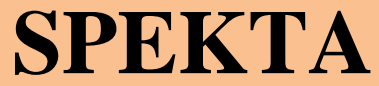

Jurnal Pengabdian Kepada Masyarakat : Teknologi dan Aplikasi

Journal homepage :

http://journal2.uad.ac.id/index.php/spekta

\title{
SISTEM INFORMASI KEUANGAN PROGRAM PENGEMBANGAN KEWIRAUSAHAAN FTI UAD
}

\author{
Amalya Nurul Khairi ${ }^{1, *}$, Farid Ma'ruf ${ }^{2}$, Syifa Fitriani ${ }^{2}$, Jefree Fahana ${ }^{3}$ \\ ${ }^{1}$ Program Studi Teknologi Pangan, Universitas Ahmad Dahlan, Bantul, Daerah Istimewa Yogyakarta, Indonesia \\ ${ }^{2}$ Program Studi Teknik Industri, Universitas Ahmad Dahlan, Bantul, Daerah Istimewa Yogyakarta, Indonesia \\ ${ }^{3}$ Program Studi Teknik Informatika, Universitas Ahmad Dahlan, Bantul, Daerah Istimewa Yogyakarta, Indonesia
}

\section{INFO ARTIKEL}

Diterima: 9 November, 2020

Direvisi: 10 November, 2020

Disetujui: 10 November, 2020

Keywords:

$P P K$;

Financial Information;

System Training;

Financial reports

\begin{abstract}
PPK FTI provides trainings to 20 tenants consisting of students and alumni of FTI UAD, then selects them into 6 selected tenants who will obtain venture capital in the form of grants, goods, business literature, mentoring, and financial information system training. This training was carried out with the aim of assisting FTI tenants especially in making financial statements. The methods in this activity are divided into three stages, first is the development of PPK FTI UAD financial information system, discussion and practice of filling information systems through offline and online training, and evaluating financial information systems and training through questionnaires on a likert scale. The results shows that most tenants are able to use the information system easily and provide positive feedback with a percentage of the statement of ease of use, features, and access in the range of easy and very easy. PPK financial information system is assessed by tenants according to tenant's needs and greatly saves financial management time. For further development, PPK FTI UAD will continue the activities on basic accounting training, information system improvement, and development of android or iOS applications.
\end{abstract}

\section{PENDAHULUAN}

Salah satu hal yang sering terjadi dan dialami oleh UMKM adalah kurang tertibnya dalam mengatur keuangan usaha (King, 1976). Keuangan usaha selalu dicampuradukkan dengan keuangan pribadi sehingga para pengusaha tidak mengetahui seberapa besar asset dan bagaimana arus kas usahanya (Nishimura, 2019). Sehingga yang terjadi selalu merasa produk setiap hari laku dan habis terjual, tetapi tidak ada uang untuk belanja kembali bahan bakunya. Hal semacam ini juga dialami oleh 6 tenan baru dari Program

\footnotetext{
* Corresponding author

E-mail address: amalya.khairi@tp.uad.ac.id

https://doi.org/10.12928/spekta.v1i2.3087
} 
Pengembangan Kewirausahaaan Fakultas Teknologi Industri Universitas Ahmad Dahlan (PPK FTI UAD) tahun 2020. PPK merupakan salah satu skim hibah pengabdian multitahun yang ditawarkan oleh kemeristekdikti yang saat ini berubah menjadi RISTEKBRIN. Tahun 2020 ini merupakan tahun pertama tim PPK FTI UAD memperoleh dana hibah ini.

PPK FTI ini memberikan pelatihan kepada 20 tenan yang terdiri dari mahasiswa dan alumni FTI UAD, kemudian menyeleksinya menjadi 6 tenan terpilih yang dianggap layak. 6 tenan terpilih tersebut akan mendapat beberapa kelebihan, diantaranya modal usaha dalam bentuk barang, literatur tentang bisnis, pendampingan serta mentoring, dan pelatihan sistem informasi keuangan. Pelatihan ini dilaksanakan dengan tujuan untuk membantu para tenan FTI khusunya dalam membuat pembukuan laporan keuangan usaha mereka. Ke depan memang sistem informasi keuangan ini tidak hanya bagi tenan PPK FTI saja, tetapi juga bisa digunakan oleh UMKM secara lebih luas lagi. Laporan keuangan UMKM, khususnya 6 tenan PPK FTI masih dilakukan secara manual dan belum akuntabel atau dilakukan berdasarkan aturan-aturan akuntansi yang berlaku.

Laporan keuangan merupakan hal yang sangat penting dalam sebuah usaha (Hubbard, Anthony Patrick, \& Varma, 2014). Seorang pengusaha dapat mengetahui usahanya dalam keadaan sehat atau sakit melalui laporan keuangan yang dibuat. Sehingga laporan keuangan perlu dibuat sebaik dan serapi mungkin. Adanya laporan keuangan yang baik dapat membantu memisahkan keuangan pribadi dengan modal usaha, omset keseharian, hingga keuntungan yang diperoleh. Laporan keuangan tidak hanya digunakan untuk pemilik usahanya saja, tetapi juga bisa digunakan oleh pihak-pihak tertentu yang dapat membantu mengembangkan usaha tersebut jauh lebih berkembang (Popkova, 2018). Laporan keuangan dapat didefinisikan sebagai hasil dari proses akuntansi yang dapat digunakan sebagai alat untuk mengkomunikasikan data keuangan atau aktivitas perusahaan kepada pihak-pihak yang berkepentingan (Hery dan Si, 2015). Terlalu pentingnya laporan keuangan ini, maka tim PPK FTI menyelenggarakan pelatihan laporan keuangan bagi 6 tenan terpilih.

Era revolusi industri 4.0 yang terjadi saat ini memaksa semua hal masuk ke dalam teknologi informasi. Selain itu, era ini mencoba menggabungkan antara teknologi otomatisasi dan teknologi cyber (STEIN, 2020). Banyak hal yang tadinya masih dikerjakan secara manual, pada era revolusi industri 4.0 ini dibuat dalam bentuk digital sehingga informasi yang diperoleh terkumpul dalam sebuah big data yang tersimpan di awan. Era digital saat ini memiliki kelebihan yang tidak dimiliki ketika menggunakan cara manual, yakni dalam hal kemudahan dan fleksibilitas dalam mengakses (Rama, 2008). Termasuk laporan keuangan yang dibangun oleh tim PPK FTI ini mencoba untuk mengikuti era kekinian yang saat ini terjadi. Sistem informasi keuangan yang dibangun dan dikembangkan oleh tim PPK FTI ini berbasis website sehingga mudah diakses, baik menggunakan laptop maupun smartphone. Sistem informasi keuangan ini juga tetap mengacu pada aturan akuntansi yang berlaku, walaupun pada versi perdana ini masih menggunakan prinsip dasarnya akuntansi yakni sebatas debet, kredit, dan omset (Brunelli dan Di Carlo, 2019).

6 tenan PPK FTI yang lolos seleksi diberikan pelatihan sistem informasi keuangan ini selama 2 kali, yakni 1 kali daring dan 1 kali luring. Tenan PPK FTI ini diarahkan langsung membuat laporan keuangan menggunakan sistem informasi yang dibuat. Tim PPK FTI berharap dengan adanya sistem informasi keuangan ini, tenan menjadi mudah dalam membuat laporan keuangan dan tentunya meminimalisir penggunaan kertas atau yang popular disebut paperless. Selain itu, adanya sistem informasi keuangan ini tenan 
menjadi lebih profesional dalam mengatur bisnisnya dan sudah tidak ada lagi campur aduk antara keuangan pribadi dengan keuangan usaha (Tracy dan Tracy, 2014). Sehingga bisnis dapat terukur dan tentunya dalam bertahan dalam jangka waktu yang lama.

\section{METODE PELAKSANAAN}

Sistem informasi keuangan ini dibuat oleh tim PPK FTI dengan tetap mengikuti kaidah dan aturan akuntansi yang berlaku (Needles, Powers, dan Crosson, 2013). Sistem informasi keuangan ini dibuat berbasis website sehingga bisa diakses dengan mudah tanpa harus menginstal terlebih dahulu. Penjelasan dan cara menggunakan sistem informasi keuangan ini diberikan kepada para tenan dalam bentuk pelatihan dan diskusi. Pelatihan ini disini dilaksanakan dengan menggunakan 2 cara, yakni secara luring dan secara daring. Pelatihan diawali secara luring atau tatap muka yang berlokasi di basecamp PPK FTI, yakni laboratorium kewirausahaan dan inovasi kampus utama UAD Yogykarta. 6 tenan diberikan penjelasan awal tentang apa itu sistem informasi keuangan hingga bagaimana membuat laporan keuangan menggunakan aplikasi ini.

Untuk lebih mematangkan dan mahir dalam menggunakan aplikasi ini, maka tim PPK FTI melaksanakan pelatihan kembali secara daring menggunakan platform Zoom meeting. Diskusi pada saat pelatihan sangat terbuka apabila ada tenan yang belum memahami atau memperoleh kesulitan ketika menggunakan aplikasi sistem informasi keuangan ini. Selain diskusi pada saat pelatihan, tim PPK FTI juga menggunakan whatsapp grup untuk berdikusi agar 6 tenan benar-benar bisa membuat laporan keuangan yang benar dengan adanya aplikasi ini.

Evaluasi penggunaan sistem informasi dan pelatihan dilakukan dengan menggunakan kuisioner berskala likert. Skala terendah adalah 1 yang menunjukkan pendapat terburuk (sangat sulit dipahami, sangat tidak sesuai, sangat tidak bermanfaat, dan lain-lain). Sedangkan nilai tertinggi adalah 5 yang menunjukkan skala terbaik penilaian (sangat sesuai, sangat mudah dipahami, sangat bermanfaat, dan lain-lain).

\section{HASIL DAN PEMBAHASAN}

\section{Profil Sistem Keuangan PPK FTI UAD}

Secara umum pengelolaan keuangan diawali dengan perencanaan keuangan yang menjadi langkah mengakumulasi sejumlah modal atau asset menjadi sumber pendapatan atau omzet dan laba bagi orang yang sedang menjalankan bisnis (Sina, 2014). Pengelolaan keuangan yang lengkap, baik, dan akuntabel dapat berdampak positif terhadap pemilik bisnis. Efek yang paling cepat dirasakan adalah peningkatan kualitan pengelolaan keuangan dan kredibilitas suatu perusahaan atau bisnis (Agustina, Setianingsih, dan Santoso, 2019). Dengan mengelola keuangan bisnis, diharapkan seorang pebisnis dapat menerapkan prinsip manajemen yang efektif dan efisien sehingga perubahan pola bisnis ke arah yang positif sehingga omzet/pendapatan yang diperoleh dapat dialokasikan secara lebih optimal (Yohana, 2014).

Sistem informasi adalah sekumpulan orang, fasilitas, media, tata laksana, teknologi, monitoring, dan pengendalian berbagai aspek agar diperoleh sistem komunikasi penting, menjalankan transaksi regular tertentu, serta memberi peringatan dini kepada pihak manajemen jika ditemukan kejadian internal yang membutuhkan penanganan segera (Jogianto, 2009). Dengan konsep sistem informasi tersebut, keuangan bisnis dapat dikelola dengan lebih efisien sehingga dapat memudahkan tenan melakukan pengendalian saldo/omzet, mengecek ketersediaan stok barang, real-time, dan akurat (Agustina, Setianingsih, dan Santoso, 2019). 
Vol. 1, No. 2, Desember 2020

Sistem informasi keuangan tenan PPK FTI UAD dirancang melalui website dengan database My SQL (My Structure Query Language) untuk memudahkan seluruh tenan dalam mengelola keuangan bisnisnya. Sistem ini dibagi menjadi dua yaitu untuk tenan dengan laman https://ppkftiuad.com/. untuk admin (Tim PPK FTI UAD) dengan laman https://ppkftiuad.com/admin. Tampak muka laman login sistem informasi ini dapat dilihat pada Gambar 1. Menurut Batubara (2012), website merupakan kumpulan situs atau halaman untuk menyampaikan info berupa teks, gambar yang bergerak atau diam, animasi, suara, dan dapat pula sekumpulan dari seluruh faktor tersebut. Penggunaan website sebagai sistem informasi memiliki beberapa kelebihan antara lain (Muharam, 2018):

a. Akses cepat kapan saja dan di mana saja.

Sistem informasi berbasis website dapat memudahkan user/tenan dan Tim PPK FTI UAD khususnya dalam hal pemilihan gadget, aplikasi/browser, dan tanpa batasan lokasi maupun waktu (real time) untuk mengaksesnya.

b. Mudah untuk Dikembangkan

Website menggunakan bahasa pemrograman yang dikuasai oleh hampir seluruh pengembang website seperti Hypertext Markup Language (HTML), Hypertext Preprocessor (PHP), Cascading Style Sheet (CSS), dan lain-lain. Karakteristik tersebut menyebabkan Tim PPK FTI UAD dapat lebih mudah melakukan pengembangan jika dirasa terdapat perbaikan yang diperlukan.

c. Pengaturan server yang mudah

Pembaruan dan pengaturan website dilakukan terpusat hanya dalam satu server. Dengan demikian Tim PPK FTI dapat lebih efisien melakukan pengelolaan sistem informasi.

d. Fleksibilitas dan kemudahan penyerapan dan penyebaran informasi

Tenan PPK FTI dapat mengiput setiap perubahan neraca keuangan yang terjadi di dalam pengembangan bisnisnya. Data tersebut akan diolah secara matematis dan disajikan kembali kepada tenan dalam bentuk yang lebih informatif.

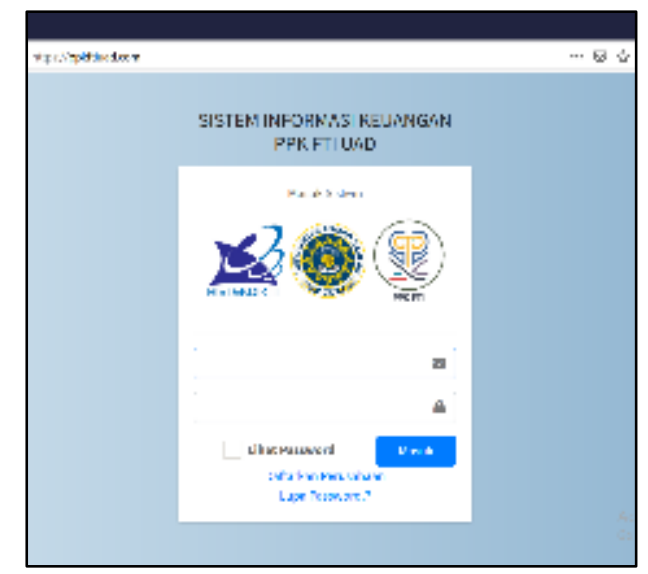

Gambar 1 Tampilan Awal Laman Sistem Informasi Keuangan Tenan PPK FTI $\mathrm{UAD}$

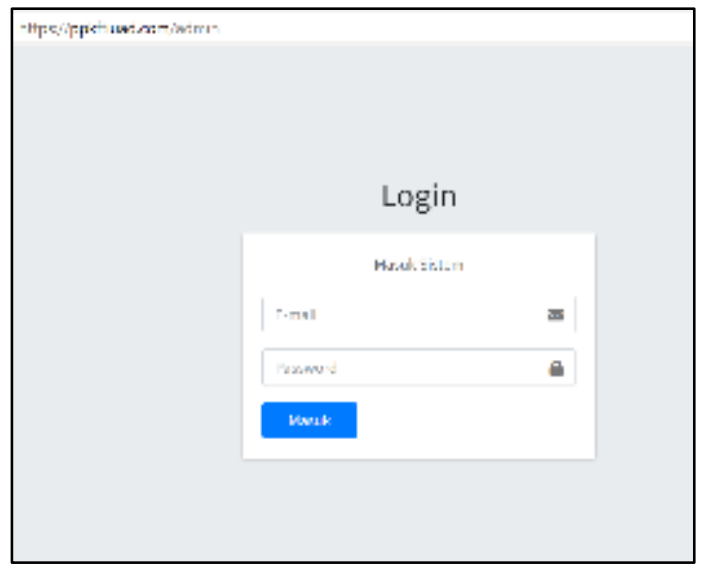

Gambar 2 Tampilan Awal Laman Sistem Informasi Keuangan Admin PPK FTI $\mathrm{UAD}$

Dalam sistem informasi keuangan ini terdapat beberapa menu utama yaitu: 
1. Dashboard, bagi tenan merupakan tampilan rekap total saldo, total transaksi, dan grafik saldo (Gambar 3). Untuk sistem informasi keuangan admin, dashboard akan menampilkan total perusahaan aktif, total transaksi tahun berjalan, jumlah perusahaan masuk, dan total saldo tahun berjalan.

2. Transaksi, hanya terdapat pada sistem informasi tenan yang merekap waktu, akun, uraian transaksi, kredit, debit, dan opsi lainnya (Gambar 4).

3. Data perusahaan, hanya terdapat pada sistem informasi admin, yang merekap nama perusahaan, pemilik, alamat, jenis usaha, status keaktifan, tanggal terdaftar, dan transaksi terbaru.

4. Laporan, hanya terdapat pada sistem informasi tenan yang berfungsi sebagai menu untuk merekap transaksi keuangan, total saldo, dan arus kas yang terjadi selama periode waktu tertentu.

5. Profil/nama akun transaksi, pada sistem informasi tenan berfungsi untuk mengedit dan menampilkan profil tenan, sedangkan pada admin merupakan menu untuk melihat rekap transaksi selama beberapa waktu tertentu yang dilakukan oleh tenan yang telah teraftar dalam sistem.

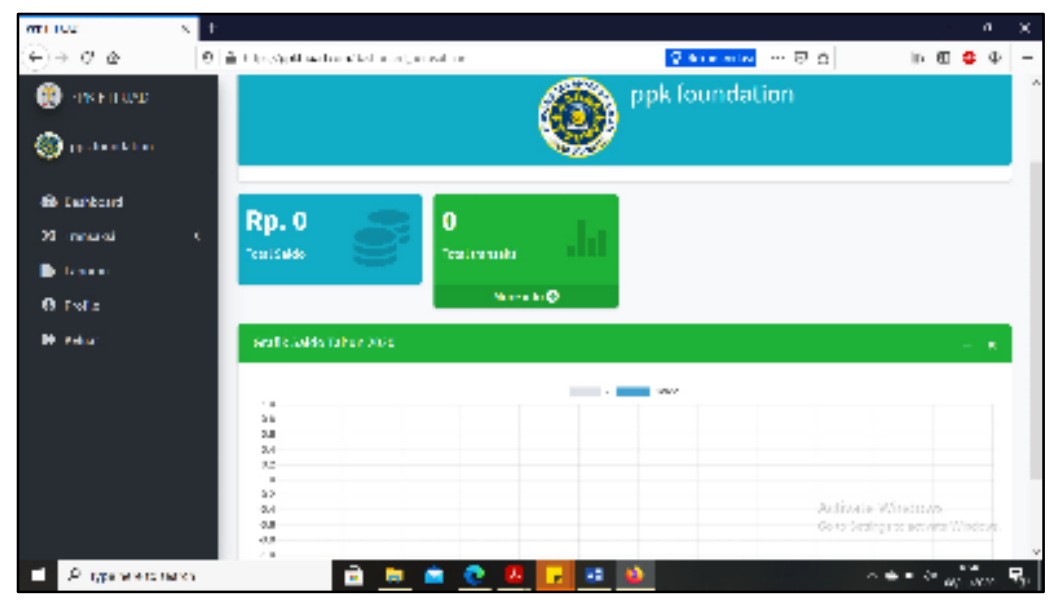

Gambar 3 Dashboard Sistem Informasi Tenan

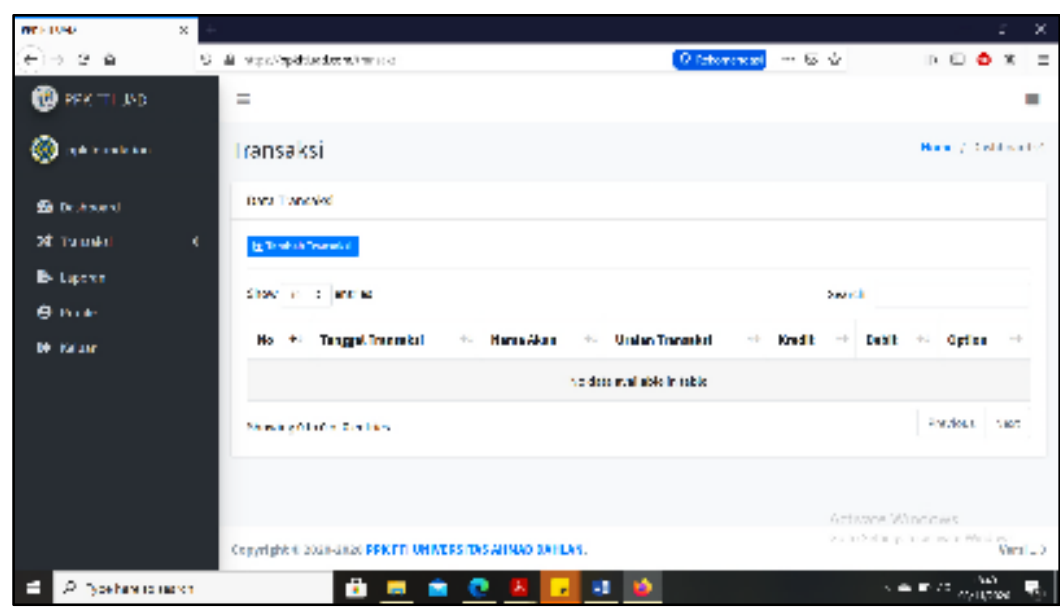

Gambar 4 Menu Transaksi Sistem Informasi Keuangan Tenan PPK FTI UAD 
Vol. 1, No. 2, Desember 2020

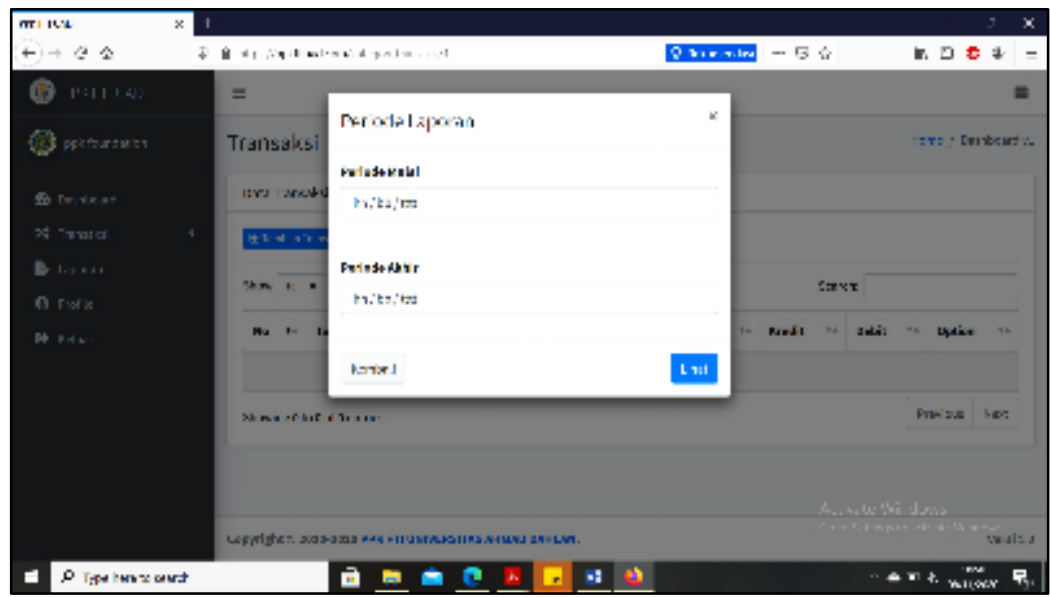

Gambar 5 Menu Laporan Sistem Informasi Keuangan Tenan PPK FTI UAD

2. Evaluasi penggunaan sistem informasi keuangan PPK FTI UAD

Evaluasi performa sistem informasi dilakukan dengan penyebaran kuisioner jenis likert dan tenan diminta memberikan penilaian dari terendah (skor 1) hingga tertinggi (skor 5). Pertanyaan dipusatkan kepada aspek kemudahan untuk kategori fitur, akses, dan penggunaan. Rekapitulasi jawaban dari tenan atas evaluasi penggunaan sistem informasi dapat dilihat pada Tabel 1 berikut.

Tabel 1 Evaluasi Penggunaan Sistem Informasi Keuangan PPK FTI UAD

\begin{tabular}{clcc}
\hline No & \multicolumn{1}{c}{ Parameter evaluasi } & $\begin{array}{c}\text { Jawaban } \\
\text { skor 4* }\end{array}$ & $\begin{array}{c}\text { Jawaban } \\
\text { skor 5** }\end{array}$ \\
\hline 1 & $\begin{array}{l}\text { Fitur/menu mudah dipahami, digunakan, dan membantu } \\
\text { pengelolaan keuangan }\end{array}$ & $75 \%$ & $25 \%$ \\
2 & Sistem informasi keuangan dapat diakses di mana saja kapan saja & $25 \%$ & $75 \%$ \\
3 & Sistem informasi sesuai kebutuhan tenan & $100 \%$ & 0 \\
4 & Sistem informasi menghemat waktu pengelolaan keuangan bisnis & $50 \%$ & $50 \%$ \\
\hline \multicolumn{4}{c}{$\begin{array}{l}* \text { *skor 4 = mudah; dapat diakses; sesuai kebutuhan; dan menghemat waktu } \\
\text { **skor 5= sangat mudah; sangat dapat diakses; sangat sesuai kebutuhan; sangat menghemat waktu }\end{array}$}
\end{tabular}

Dari Tabel 2 tersebut dapat diperoleh informasi bahwa fitur/menu pada sistem informasi mudah dipahami, digunakan, dan membantu pengelolaan keuangan yang ditandai dengan jawaban skor 4 (mudah) sebanyak $75 \%$ dan $25 \%$ menjawab skor 5 (sangat mudah). Sedangkan kemampuan sistem informasi untuk diakses di mana saja dan kapan saja sangat baik, ditandai dengan jawaban skor 5 lebih banyak (75\%) dibandingkan skor 4 (25\%). Tenan memberikan pendapat bahwa sistem informasi sesuai dengan kebutuhan tenan (100\%; skor 4) dan dapat menghemat waktu pengelolaan keuangan bisnis (50\% skor 4 dan 50\% skor 5). Dengan demikian dapat ditarik kesimpulan bahwa tenan memberikan umpan balik yang baik pada penggunaan sistem informasi keuanganan yang dikembangkan Tim PPK FTI UAD.

3. Pelaksanaan pelatihan sistem informasi keuangan PPK FTI UAD secara luring dan daring 
Menurut Firman et al. (2019) kegiatan pelatihan penyusunan laporan keuangan dapat meningkatkan kompetensi peserta pelatihan khususnya dalam hal pengelolaan keuangan, perapihan pencatatan, pembukuan, dan laporan keuangan yang berkualitas dan benar. Pelatihan luring ini dilaksanakan pada tanggal 5 September 2020 dengan metode penyampaian materi dan praktik pengisian sistem informasi keuangan secara langsung. Gambaran pelaksanaan pelatihan dapat dilihat pada Gambar 6. Materi yang disampaikan oleh Tim PPK FTI UAD adalah tentang pengenalan sistem informasi dan fungsi dari menu-menu yang ada pada sistem. Peserta dari pelatihan ini adalah satu orang perwakilan dari enam kelompok tenan yang telah terpilih mendapatkan hibah pengembangan usaha dan dilaksanakan di sekretariat PPK, Laboratorium Kewirausahaan FTI UAD. Pembatasan peserta ini dilakukan karena situasi pandemi yang masih belum reda. Tenan merupakan mahasiswa aktif dan alumni FTI UAD yang telah atau baru akan memiliki usaha. Daftar peserta pelatihan ini dapat dilihat pada Tabel 2 .

Tabel 2 Peserta Pelatihan Luring Sistem Informasi Keuangan PPK FTI UAD

\begin{tabular}{clll}
\hline No & \multicolumn{1}{c}{ Nama Usaha } & \multicolumn{1}{c}{ Jenis Usaha } & \multicolumn{1}{c}{ Status } \\
\hline 1 & Bening Qalbu & Training/jasa & Alumni \\
2 & Dermayu Catering Jogja & Kuliner & Alumni \\
3 & Ngumbah Tapak & Jasa/fashion & Mahasiswa \\
4 & Muvon Multimedia & Multimedia & Mahasiswa \\
5 & Chicken Lemon & Kuliner & Alumni \\
6 & Clythoria Yoghurt & Kuliner & Mahasiswa \\
\hline
\end{tabular}
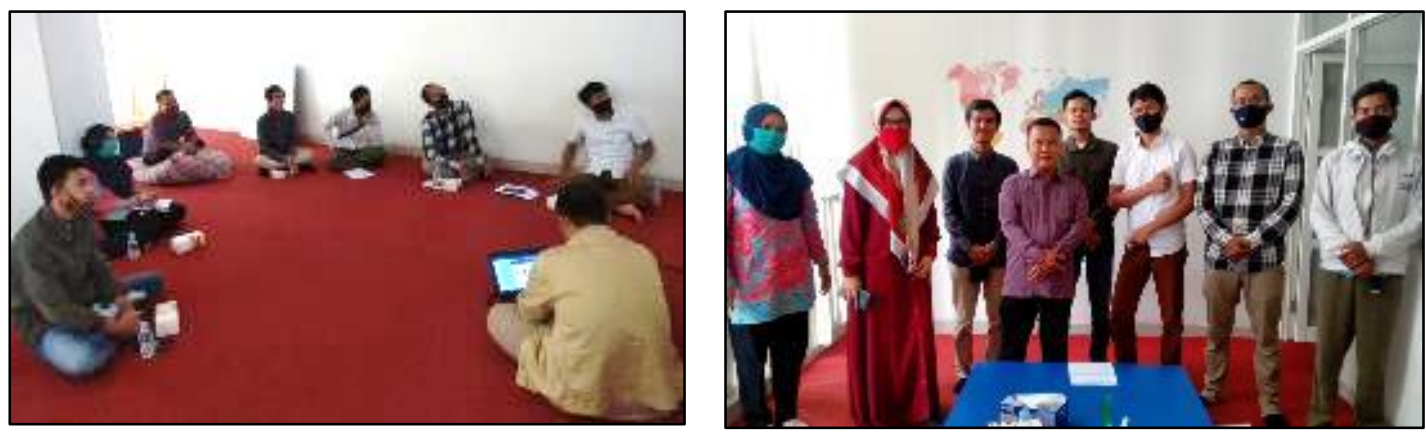

Gambar 6 Suasana Pelatihan Sistem Informasi Keuangan

Pelatihan daring dilaksanakan melalui aplikasi Zoom Meeting dengan materi memperdalam teknik pengisian data dan monitoring perkembangan bisnis bagi para tenan. Pelatihan ini masih diikuti oleh 6 tim tenan lolos hibah PPK FTI UAD, akan tetapi tidak dibatasi keikutsertaannya (ketua tim dan anggota diijinkan hadir). Pelaksanaan pelatihan secara luring dan daring ini dievaluasi dengan menjaring umpan balik peserta terhadap kemudahan materi pelatihan untuk dipahami. Hasil penjaringan umpan balik dari tenan dapat terlihat pada Gambar 7 berikut. 


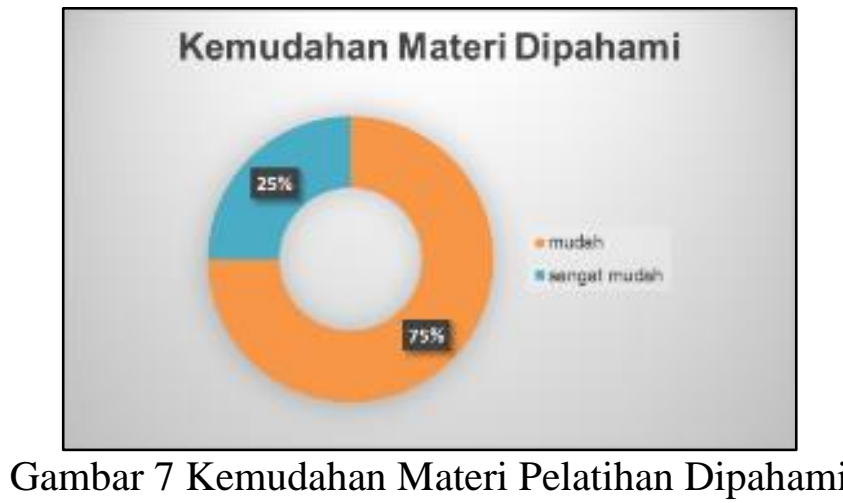

Dari Gambar 7 di atas dapat disimpulkan materi pelatihan daring dan luring penggunaan sistem informasi keuangan PPK FTI mudah dipahami (75\%), dan sebanyak $25 \%$ peserta menyatakan sangat mudah dipahami. Penjaringan umpan balik tenan juga mengumpulkan saran dan masukan dari tenan terhadap perbaikan sistem informasi yang dapat dirangkum sebagai berikut:

a. Penggunaan akun untuk login cukup menggunakan akun pembelian dan penjualan saja sehingga tidak memerlukan banyak akun

b. Perlu membuat aplikasi yang dapat dioperasikan pada Android dan iOS untuk lebih memudahkan pengisian sistem informasi

c. Diperlukan pemberian materi tentang pendekatan dasar-dasar akuntansi sebagai landasan pencatatan keuangan bisnis sehingga saat akan menuliskan dan mengelompokkan transaksi serta item tenan menuliskanya sesuai dengan pemahaman yang benar.

d. Menu pada sistem informasi sudah baik, hanya perlu penambahan jenis usaha pada menu profil tenan

\section{KESIMPULAN}

Sistem informasi keuangan PPK FTI UAD terdiri dari sistem informasi bagi tenan dan bagi admin/Tim PPK FTI UAD. Sistem informasi tersebut telah dapat digunakan dan mendapat umplan balik positif yang ditandai dengan pendapat tenan akan kemudahan pengoperasian sistem dari aspek fitur/menu, pemahanman fungsi, dan kecepatan penggunaan kapan dan di mana saja. Sebelum menggunakan sistem informasi, tenan diberi pelatihan luring maupun daring. Setelah menggunakan sistem informasi selama beberapa waktu, tenan memberi masukan terkait penggunaan akun, pembuatan aplikasi android dan IoS, dan diperlukannya pelatian mengenai dasar akuntansi agar tenan dapat mengelola keuangan sesuai dengan kaidah yang benar. Tindak lanjut dari kegiatan ini adalah dengan mem-follow up masukan dari tenan tersebut khususnya dalam hal penyempurnaan sistem, pembuatan aplikasi Android/iOS, dan pelatihan pengelolaan keuangan menggunakan dasar akuntansi.

\section{UCAPAN TERIMA KASIH}

Kami haturkan terima kasih kepada Ristek-BRIN sebagai pemberi dana kegiatan pengabdian multi-tahun skema Program Pengembangan Kewirausahaan Fakultas Teknologi Industri Universitas Ahmad Dahlan (PPK FTI UAD). Kami juga menghaturkan terima kasih kepada Lembaga Penelitian dan Pengabdian Masyarakat Universitas Ahmad Dahlan (LPPM UAD), Dekan, Ketua Program Studi, dan pengampu 
Mata Kuliah Kewirausahaan FTI UAD yang telah memberikan dukungan, arahan, fasilitas, dan bantuan untuk terselenggaranya program ini dengan baik.

\section{DAFTAR PUSTAKA}

Agustina, Y., Setianingsih, S., Santoso, Y.D. (2019). Pelatihan Penyusunan Laporan Keuangan Bagi Entitas Mikro, Kecil, dan Menengah Bidang Usaha Dagang pada UMKM Binaan Pusat Inkubasi Bisnis Syariah Majelis Ulama Indonesia. INTERVENSI KOMUNITAS. Vol. 1, No, 1 hal 1-13

Batubara, F., A. (2012). Perancangan Website pada PT Ratu Enim Palembang. REINTEK. Vol.7, no.1 hal 15-27.

Brunelli, S., \& Di Carlo, E. (2019). Accountability, Ethics and Sustainability of Organizations: New Theories, Strategies and Tools for Survival and Growth. Springer Nature.

Firman, I., Marliana, R., Almunawwaroh, M. (2016). Pelatihan Managemen Keuangan di Pondok Pesantren Menggunakan Aplikasi Berbasis Web Terintegrasi dengan Barcode System dan SMS Gateway. Jurnal Siliwangi Vol.2 No.2 hal 126-131.

Hery, S., \& Si, M. (2015). Praktis Menyusun Laporan Keuangan. Prekatis Menysun Laporan Keuangan Cepat \& Mahir Menyajikan.

Hubbard, R. G., Anthony Patrick, O., \& Varma, S. (2014). Money, banking, and the financial system. Pearson Boston.

Jogianto, H.,M. (2009). Sistem Teknologi Informasi. Penerbit Andi

King, B. G. (1976). Modern Accounting: Accounting as the Information System for Technological Change. JSTOR.

Muharam, A. (2018). Keunggulan Aplikasi Web. https://www.logique.co.id/blog/2018/07/27/keunggulan-aplikasi-web/. Diakses 8 November 2020

Needles, B. E., Powers, M., \& Crosson, S. V. (2013). Principles of accounting. Cengage Learning.

Nishimura, A. (2019). Management, Uncertainty, and Accounting. Springer.

Popkova, E. G. (2018). The future of the global financial system: Downfall or Harmony (Vol. 57). Springer.

Rama, J. (2008). Sistem Informasi Akuntansi 1. Penerbit Salemba.

Sina, P. G. (2014). Motivasi Sebagai Penentu Perencanaan Keuangan (Suatu Studi Pustaka). Jurnal Ilmiah Akuntansi Dan Bisnis, vol 9(1), hal 42-48.

STEIN, S. (2020). BLOCKCHAIN, ARTIFICIAL INTELLIGENCE AND FINANCIAL SERVICES: Implications and Applications for... Finance and Accounting Professionals. SPRINGER.

Tracy, J. A., \& Tracy, T. C. (2014). How to read a financial report: wringing vital signs out of the numbers. John Wiley \& Sons.

Yohana, C. (2014). Pelatihan Mengelola Keuangan Sederhana Bagi Pengusaha Kecil di Desa Cibadak. Jurnal Sarwahita, vol 11(2), hal 67-70. 
SPEKTA

Jurnal Pengabdian Kepada Masyarakat : Teknologi dan Aplikasi

Vol. 1, No. 2, Desember 2020

Halaman ini sengaja dikosongkan 